\title{
Clinical impact of (18)F-choline PET/CT in patients with recurrent prostate cancer
}

Soyka, Jan D ; Muster, Marco A ; Schmid, Daniel T ; Seifert, Burkhardt ; Schick, Ulrike ; Miralbell, Raymond ; Jorcano, Sandra ; Zaugg, Kathrin ; Seifert, Hans-Helge ; Veit-Haibach, Patrick ; Strobel, Klaus ; Schaefer, Niklaus G ; Husarik, Daniela B ; Hany, Thomas F

\begin{abstract}
PURPOSE: To investigate the clinical value of (18)F-fluorocholine PET/CT (CH-PET/CT) in treatment decisions in patients with recurrent prostate cancer (rPCA). METHODS: The study was a retrospective evaluation of 156 patients with $\mathrm{rPCA}$ and $\mathrm{CH}-\mathrm{PET} / \mathrm{CT}$ for restaging. Questionnaires for each examination were sent to the referring physicians 14-64 months after examination. Questions included information regarding initial extent of disease, curative first-line treatment, and the treatment plan before and after CH-PET/CT. Additionally, PSA values at diagnosis, after initial treatment, before $\mathrm{CH}-\mathrm{PET} / \mathrm{CT}$ and at the end of follow-up were also obtained from the questionnaires. RESULTS: Mean follow-up was 42 months. The mean Gleason score was 6.9 at initial diagnosis. Initial treatment was: radical prostatectomy in 110 patients, radiotherapy in 39, and combined prostatectomy and radiotherapy in 7. Median PSA values before CH-PET/CT and at the end of follow-up were $3.40 \mathrm{ng} / \mathrm{ml}$ and 0.91 $\mathrm{ng} / \mathrm{ml}$. PSA levels remained stable, decreased or were below measurable levels in 108 patients. PSA levels increased in 48 patients. In 75 of the 156 patients $(48 \%)$ the treatment plan was changed due to the $\mathrm{CH}-\mathrm{PET} / \mathrm{CT}$ findings. In 33 patients the therapeutic plan was changed from palliative treatment to treatment with curative intent. In 15 patients treatment was changed from curative to palliative. In 8 patients treatment was changed from curative to another strategy and in 2 patients from one palliative strategy to another. In 17 patients the treatment plan was adapted. CONCLUSION: CH-PET/CT has an important impact on the therapeutic strategy in patients with rPCA and can help to determine an appropriate treatment.
\end{abstract}

DOI: https://doi.org/10.1007/s00259-012-2083-2

Posted at the Zurich Open Repository and Archive, University of Zurich

ZORA URL: https://doi.org/10.5167/uzh-62296

Journal Article

Published Version

Originally published at:

Soyka, Jan D; Muster, Marco A; Schmid, Daniel T; Seifert, Burkhardt; Schick, Ulrike; Miralbell, Raymond; Jorcano, Sandra; Zaugg, Kathrin; Seifert, Hans-Helge; Veit-Haibach, Patrick; Strobel, Klaus; Schaefer, Niklaus G; Husarik, Daniela B; Hany, Thomas F (2012). Clinical impact of (18)F-choline $\mathrm{PET} / \mathrm{CT}$ in patients with recurrent prostate cancer. European Journal of Nuclear Medicine and Molecular Imaging, 39(6):936-943.

DOI: https://doi.org/10.1007/s00259-012-2083-2 


\title{
Clinical impact of ${ }^{18} \mathrm{~F}$-choline PET/CT in patients with recurrent prostate cancer
}

\author{
Jan D. Soyka • Marco A. Muster • Daniel T. Schmid • Burkhardt Seifert • Ulrike Schick • \\ Raymond Miralbell • Sandra Jorcano • Kathrin Zaugg • Hans-Helge Seifert • Patrick Veit-Haibach • \\ Klaus Strobel • Niklaus G. Schaefer • Daniela B. Husarik • Thomas F. Hany
}

Received: 25 November 2011 / Accepted: 1 February 2012 /Published online: 14 March 2012

(C) Springer-Verlag 2012

\begin{abstract}
Purpose To investigate the clinical value of ${ }^{18} \mathrm{~F}$-fluorocholine PET/CT (CH-PET/CT) in treatment decisions in patients with recurrent prostate cancer (rPCA).

Methods The study was a retrospective evaluation of 156 patients with rPCA and CH-PET/CT for restaging. Questionnaires for each examination were sent to the referring physicians 14-64 months after examination. Questions included information regarding initial extent of disease,
\end{abstract}

J. D. Soyka $(\bowtie) \cdot$ M. A. Muster • D. T. Schmid · P. Veit-Haibach •

K. Strobel • N. G. Schaefer • T. F. Hany

Department of Nuclear Medicine, University Hospital Zurich,

Raemistrasse 100 ,

8091 Zurich, Switzerland

e-mail: jan.soyka@gmx.ch

B. Seifert

Division of Biostatistics, Institute of Social and Preventive

Medicine, University of Zurich,

Zurich, Switzerland

U. Schick $\cdot$ R. Miralbell

Department of Radiation-Oncology, University Hospital Geneva, Geneva, Switzerland

\section{S. Jorcano}

Department of Radiation-Oncology, Instituto Oncológico Teknon, Barcelona, Spain

K. Zaugg

Department of Radiation-Oncology, University Hospital Zurich,

Zurich, Switzerland

\section{H.-H. Seifert}

Department of Urology, University Hospital Zurich,

Zurich, Switzerland

D. B. Husarik

Department of Radiology, University Hospital Zurich,

Zurich, Switzerland curative first-line treatment, and the treatment plan before and after CH-PET/CT. Additionally, PSA values at diagnosis, after initial treatment, before CH-PET/CT and at the end of follow-up were also obtained from the questionnaires. Results Mean follow-up was 42 months. The mean Gleason score was 6.9 at initial diagnosis. Initial treatment was: radical prostatectomy in 110 patients, radiotherapy in 39, and combined prostatectomy and radiotherapy in 7. Median PSA values before CH-PET/CT and at the end of follow-up were $3.40 \mathrm{ng} / \mathrm{ml}$ and $0.91 \mathrm{ng} / \mathrm{ml}$. PSA levels remained stable, decreased or were below measurable levels in 108 patients. PSA levels increased in 48 patients. In 75 of the 156 patients $(48 \%)$ the treatment plan was changed due to the CH-PET/CT findings. In 33 patients the therapeutic plan was changed from palliative treatment to treatment with curative intent. In 15 patients treatment was changed from curative to palliative. In 8 patients treatment was changed from curative to another strategy and in 2 patients from one palliative strategy to another. In 17 patients the treatment plan was adapted.

Conclusion CH-PET/CT has an important impact on the therapeutic strategy in patients with rPCA and can help to determine an appropriate treatment.

Keywords ${ }^{18} \mathrm{~F}$-Choline PET/CT $\cdot$ Recurrent prostate cancer . Clinical impact

\section{Introduction}

Adenocarcinoma of the prostate (PCA) is the most common malignant tumour in men in the United States, and is associated with the second highest number of cancer deaths per year following bronchial carcinoma [1]. Nevertheless, current staging and restaging procedures especially regarding 
nodal involvement and distant metastases still have many limitations, leading to insufficiencies in treatments with curative intent. Consequently as many as $19-53 \%$ of patients initially treated with curative intent suffer from recurrent disease [2-5]. Rising levels of prostate-specific antigen (PSA) in the blood serum of patients indicate tumour progression, often long before imaging modalities can detect any abnormalities. In this biochemical relapse situation there are no guidelines giving any conclusive suggestions regarding imaging procedures. Bone scintigraphy and $\mathrm{CT}$ are both insensitive and show reliable results only at

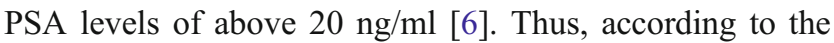
current guidelines, these examinations can safely be omitted. Depending solely on the kinetics of the rising PSA levels the decision is made whether a local recurrence or a distant recurrence is present. If a local recurrence is suspected patients may qualify for a salvage procedure of the prostate fossa. If distant disease is suspected only palliative antihormonal treatment is suggested. MRI with an endorectal coil shows reliable results in the evaluation of the prostate fossa, but is not routinely recommended by the guidelines [6-8].

${ }^{18} \mathrm{~F}$-Choline PET/CT $(\mathrm{CH}-\mathrm{PET} / \mathrm{CT})$ is a promising examination tool for the detection of recurrent PCA (rPCA) [9]. Even though the exact role of the examination is still a matter of discussion, it seems that CH-PET/CT starts playing a role in the management of patients with biochemical relapse $[10,11]$. Several studies have demonstrated that $\mathrm{CH}-$ PET/CT labelled with either ${ }^{11} \mathrm{C}[12,13]$ or with ${ }^{18} \mathrm{~F}[14$, 15] can detect tumour recurrence at PSA levels of above $2 \mathrm{ng} / \mathrm{ml}$, giving the opportunity for a salvage procedure with curative intent at an early time point of the recurrence [12-15]. In certain constellations, tumour recurrence can even be detected if PSA levels are below $2 \mathrm{ng} / \mathrm{ml}$, but the detection rate in these patients is only approximately 30 $40 \%[13,16]$. Even though localized treatment of distant metastases is currently not an established therapy, several studies of CH-PET/CT-guided radiation therapy and salvage surgery have already been published with promising results [17-19]. We therefore retrospectively analysed the impact of the results of $\mathrm{CH}-\mathrm{PET} / \mathrm{CT}$ examinations performed at our institution on treatment decisions.

\section{Materials and methods}

This study was conducted according to the local ethics committee guidelines for retrospective analyses. Between March 2003 and October 2007, we performed 353 CH$\mathrm{PET} / \mathrm{CT}$ examinations in patients with PCA. Of these patients, 229 had rising PSA levels after initial treatment with surgery, radiation therapy or both, indicating recurrent disease. Since no recommendations were given by the guidelines, previous conventional imaging (e.g. bone scan, MRI, CT) was not required for inclusion in our follow-up study [6-8]. Questionnaires were created and sent to the referring physicians in December 2008, 14 months after the scan of the last included patient. After a waiting period of approximately 4 weeks, those physicians who had not returned the questionnaires were reminded once by telephone.

\section{CH-PET/CT}

All the data were acquired on a combined PET/CT in-line system (Discovery LS or Discovery ST; GE Health Systems, Milwaukee, WI). These dedicated integrated systems comprise a PET scanner (GE Advance Nxi) and a multislice helical CT scanner (LightSpeed plus or LightSpeed 16), and acquire coregistered $\mathrm{CT}$ and PET images in one session. No oral or intravenous CT contrast agent was used. Patients were examined in the supine position. The unenhanced CT scans were acquired with the following parameters: $80 \mathrm{~mA}$, $140 \mathrm{kV}, 0.5 \mathrm{~s}$ tube rotation, $4.25 \mathrm{~mm}$ section thickness, $867 \mathrm{~mm}$ scan length, and 22.5 second data acquisition time. The CT scans were acquired during breath-hold in the normal expiration position, and scanning included the area from the head to the pelvic floor. The PET emission scan started 3-4 min after injection of a standard dose of $200-300 \mathrm{MBq}$ ${ }^{18}$ F-fluorocholine. After acquisition of a partial body scan (pelvic floor to vertex), approximately 1520 min after injection a second partial body scan with the same scan length was acquired, without taking the patient off the examination table and without voiding of the bladder. The PET images were acquired starting at the level of the pelvis, with an acquisition time of $3 \mathrm{~min}$ for the emission scan per cradle position and a one-slice overlap. The CT data were used for attenuation correction, and images were reconstructed using a standard 2-D iterative algorithm (ordered subsets expectation maximization).

For image fusion, 4.25-mm thick CT image slices were reconstructed. Images were then transferred to a commercially available workstation (GE Advantage). These workstations allow simultaneous data evaluation of early- and late-phase PET studies with the corresponding CT images as a single procedure and in image fusion mode. Both partial body PET scans were fused with the CT scan and read side by side. The early scan was primarily used for the evaluation of the prostate fossa because at this time the tracer would not have arrived in the bladder. The late scan was used for better differentiation between reactive/Inflammatory and malignant lymph nodes [20]. A visually detectable washout of the tracer from lymph nodes over time was considered as benign, whereas a persisting or increasing tracer activity in the lymph nodes was considered as a sign for malignancy. 
Diagnostic findings

All CH-PET/CT examinations were reported by a dual boardcertified radiologist/nuclear medicine physician with 5 years of experience in CH-PET/CT reading. The findings from each $\mathrm{CH}-\mathrm{PET} / \mathrm{CT}$ examination were collected from these written reports. Although performed in some patients, validation of the findings from CH-PET/CT with other imaging methods or with a histological work-up could not be obtained consistently due to the retrospective nature of the study, and was therefore not required for inclusion in the study.

\section{Questionnaire}

The questionnaire consisted of questions regarding the following topics:

1. Initial TNM stage and initial grading according to Gleason

2. Initial therapies and antihormonal treatments

3. Treatment after CH-PET/CT and hypothetical treatment if no CH-PET/CT had been available

4. PSA values at diagnosis, after initial therapy, before $\mathrm{CH}$ $\mathrm{PET} / \mathrm{CT}$ and at the end of follow-up

The referring physicians were asked to indicate the therapeutic strategy in the patient as it had been defined after the $\mathrm{CH}-\mathrm{PET} / \mathrm{CT}$. Then they were asked to define a hypothetical therapeutic strategy assuming the results of the CH-PET/CT had not been available. Additionally, they were asked to indicate whether the chosen treatment plan had been influenced by the CH-PET/CT scan. A change in therapy consisted of the choice of a different therapeutic strategy (e.g. antihormonal therapy to radiation therapy) or of an alteration within a therapeutic strategy (e.g. adaptation of the radiation field).

Statistical analysis

General descriptive statistics were used to calculate mean age, mean follow-up time and median PSA values. Due to the substantial skew of the PSA value distribution, logarithmic transformation was performed for all PSA values to obtain a symmetric distribution. A constant value of 0.01 was added to all PSA values before transformation to make values of zero valid for transformation. PSA ratios from PSA values before and after CH-PET/CT were calculated by subtracting the log-transformed values from after $\mathrm{CH}$ $\mathrm{PET} / \mathrm{CT}$ from the log-transformed values from before $\mathrm{CH}$ PET/CT. Nonparametric testing (Mann-Whitney $U$ test) was used to compare PSA ratios among different patient subgroups. The Wilcoxon signed ranks test was used for comparison of PSA values before and after CH-PET/CT. $P$ values $<0.05$ were considered significant. All statistical analyses were performed using SPSS for Windows, release 18.0.0 (SPSS, Chicago, IL)

\section{Results}

Disease characteristics

A total of 163 questionnaires were returned by the referring physicians. Seven patients with returned questionnaires had to be excluded because of missing PSA values before $\mathrm{CH}$ $\mathrm{PET} / \mathrm{CT}$ and/or at the end of follow-up. Finally, 156 of 229 completed questionnaires (68\%) were evaluated (Fig. 1).
Fig. 1 Patient inclusion pathway

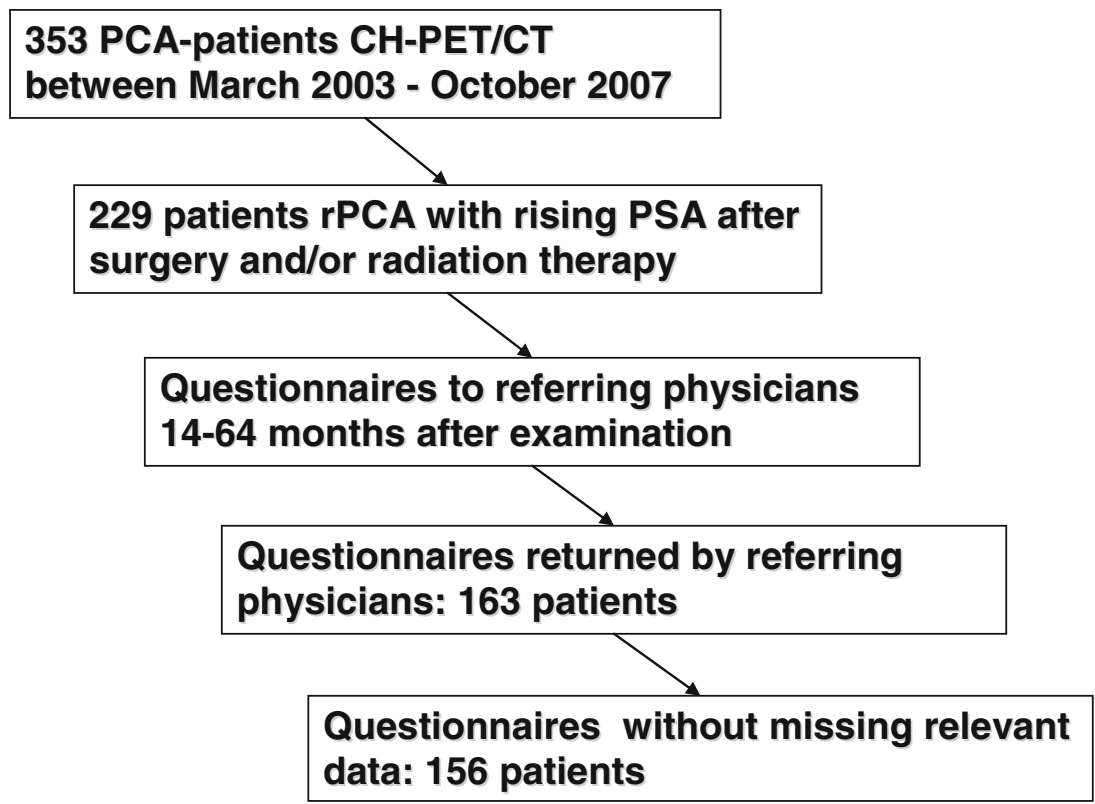


Table 1 TNM stages of our patients. Patients with MX were treated as M0 in this table. Five patients had distant metastases (three patients T3 N1 M1, one patient T4 N0 M1, and one patient T4 Nx M1)

\begin{tabular}{lllll}
\hline T stage & N0 & N1 & Nx & M1 \\
\hline 1 & 14 & 0 & 0 & 0 \\
2 & 52 & 5 & 6 & 0 \\
3 & 61 & 6 & 6 & 3 \\
4 & 2 & 2 & 1 & 2 \\
$\mathrm{x}$ & 0 & 0 & 1 & 0 \\
\hline
\end{tabular}

The mean follow-up was 42 months (range 14-64 months). The mean age of the patients at the time of CH-PET/CT was 66 years (range 48-81 years). At diagnosis the most frequent tumour stage was T3 N0 M0 (Table 1), and the mean Gleason score was 6.91. The most frequently represented gleason scores were Gleason $7(n=52)$, Gleason $6(n=38)$ and Gleason 8 (=27) (Fig. 2). Initial treatment consisted of radical prostatectomy in 110 patients, radiotherapy in 39 patients and a combination of both in 7 patients.

\section{Diagnostic performance}

Positive findings on CH-PET/CT were reported in 124 of the 156 patients (79\%): 63 patients $(40 \%)$ had a local recurrence only, 27 patients (17\%) had lymphatic metastases only, and 9 patients $(6 \%)$ had metastases to the bones only, 14 patients $(8 \%)$, had a local recurrence plus nodal metastases, 8 patients $(5 \%)$ had local recurrence plus bony metastases, and 4 patients $(3 \%)$ had tumour manifestations in the prostate fossa, lymph nodes and bones.

Actual vs. hypothetical treatment

In $75 / 156$ patients (48\%) the treatment plan was changed. In 33 patients $(21 \%)$ treatment was changed from palliative treatment to treatment with curative intent (surgery, radiation therapy, high-intensity focused ultrasound and combined therapies). In 15 patients (10\%) treatment was altered from curative to palliative (watchful waiting, antihormonal treatment or chemotherapy). In 8 patients (5\%) treatment was changed from one curative modality to another and in 2 patients $(1 \%)$ from one palliative modality to another. In 17 patients (11\%) the treatment plan was adapted (Table 2). In 8 patients $(6 \%)$ a change in treatment was indicated even though CH-PET/CT showed no abnormities. In three of these patients (initially operated upon) who were scheduled for radiotherapy before CH-PET/CT, the radiation field was adapted. In one patient (initially operated upon) radiotherapy was changed to surgery. In one patient (initially operated upon) who was scheduled for surgery, the surgical procedure was adapted. In one patient

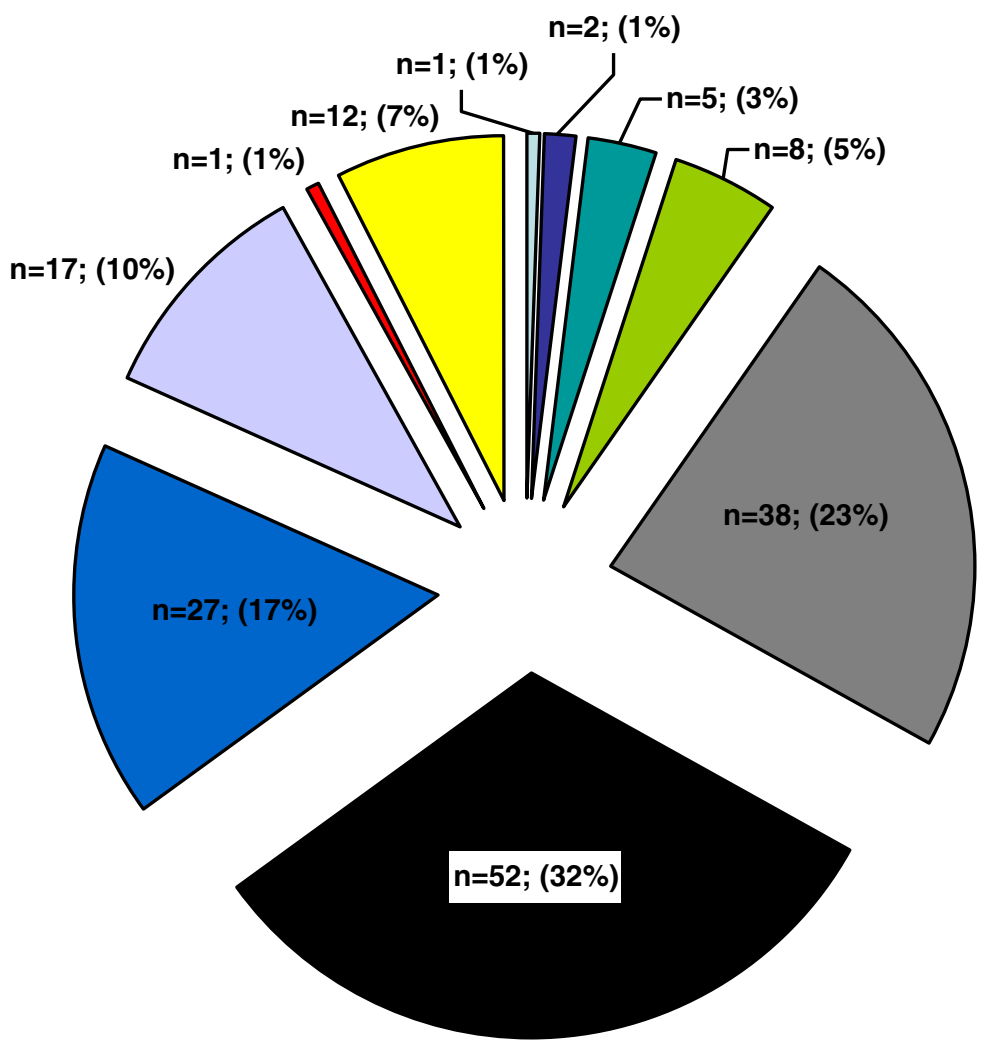

Gleason 2

Gleason 3

$\square$ Gleason 4

Gleason 5

Gleason 6

Gleason 7

$\square$ Gleason 8

$\square$ Gleason 9

$\square$ Gleason 10

$\square$ Gleason $\mathrm{x}$

Fig. 2 The distribution of Gleason scores 
Table 2 Treatments with CH-PET/CT and hypothetical treatments without CH-PET/CT as indicated by the referring physicians

\begin{tabular}{llllllll}
\hline & $\begin{array}{l}\text { Watchful waiting } \\
\text { (no therapy) }\end{array}$ & $\begin{array}{l}\text { Antihormonal } \\
\text { treatment }\end{array}$ & $\begin{array}{l}\text { Radiation } \\
\text { therapy }\end{array}$ & Surgery & $\begin{array}{l}\text { High-intensity } \\
\text { focused } \\
\text { ultrasound }\end{array}$ & $\begin{array}{c}\text { Chemotherapy } \\
\text { Antihormonal } \\
\text { and radiation } \\
\text { therapy }\end{array}$ & $\begin{array}{l}\text { Surgery and } \\
\text { radiation } \\
\text { therapy }\end{array}$ \\
\hline $\begin{array}{l}\text { Therapy with } \\
\begin{array}{c}\text { CH-PET/CT } \\
\text { Hypothetical therapy } \\
\text { without CH-PET/CT }\end{array}\end{array}$ & 19 & 37 & 59 & 11 & 6 & 1 & 22 \\
\hline
\end{tabular}

(initially operated upon) who was scheduled for radiotherapy and additional antihormonal treatment, the strategy was changed to antihormonal treatment only. In one patient (initially treated with radiotherapy) antihormonal treatment was changed to watchful waiting. In one patient (initially operated upon) scheduled for antihormonal treatment this treatment was adapted.

PSA values

Table 3 presents the PSA values in our patients at the different time-points. Since two patients had extraordinarily high PSA values at the end of follow-up (150 ng/ml in one, and $334.8 \mathrm{ng} / \mathrm{ml}$ in the other), median PSA values were calculated as well as mean values in order to correct for the overwhelming influence of these two patients' values on the results. PSA levels before CH-PET/CT were significantly higher than those at the end of follow-up $(P<0.001$; Wilcoxon signed ranks test). At the end of follow-up, PSA values had declined in 107 patients (69\%) due to subsequent therapies. Of these 107 patients, $16(10 \%)$ had values below the measurable threshold, $1(1 \%)$ had a stable PSA value and 48 (31\%) showed increased PSA levels.

PSA values before CH-PET/CT were significantly higher $(P<0.001$, Mann-Whitney $U$ test $)$ in patients with a positive $\mathrm{CH}-\mathrm{PET} / \mathrm{CT}$ scan (median PSA $4.50 \mathrm{ng} / \mathrm{ml}$, range $0.15-$ $296.61 \mathrm{ng} / \mathrm{ml}$ ) than in those with a negative scan (median PSA $1.20 \mathrm{ng} / \mathrm{ml}$, range $0.1-30.3 \mathrm{ng} / \mathrm{ml}$ ). However, there was no significant difference in the PSA ratios before and after $\mathrm{CH}-\mathrm{PET} / \mathrm{CT}$ between patients with a positive $\mathrm{CH}-\mathrm{PET} / \mathrm{CT}$ scan and those with a negative scan $(P=0.70$, MannWhitney $U$ test). These two groups did not differ regarding initial PSA levels at the time of diagnosis $(P=0.48$, Mann-
Whitney $U$ test). There was also no significant difference in the PSA ratios before and after $\mathrm{CH}-\mathrm{PET} / \mathrm{CT}$ between patients in whom the intended treatment plan was changed after CH-PET/CT $(n=75,48 \%)$ and those in whom treatment was not changed $(n=81,52 \% ; P=0.68$, MannWhitney $U$ test). Again the PSA values at the time of primary diagnosis were not significantly different between these two groups ( $P=0.67$, Mann-Whitney $U$ test $)$

\section{Discussion}

To our knowledge this retrospective analysis is the first to analyse the clinical impact of CH-PET/CT on treatment decisions in patients with rPCA. We obtained our data using questionnaires sent to those physicians who had referred their patients for a CH-PET/CT scan to our institution. The referring physicians were asked to provide information about the therapy, which had been performed after $\mathrm{CH}$ $\mathrm{PET} / \mathrm{CT}$ and to determine a hypothetical therapeutic management without the information obtained from the $\mathrm{CH}$ PET/CT scan. With this method we were able to demonstrate a strong clinical impact of CH-PET/CT. The results of our examination led to changes in the therapy in $48 \%$ of patients, which consisted of adaptation of the current treatment regimen or even complete change in the therapeutic approach. Even though a comparison with a non-CH-PET/ $\mathrm{CT}$ control group was not possible due to the retrospective study design, the therapies performed after CH-PET/CT were effective since a significant decline in the mean PSA values after the $\mathrm{CH}-\mathrm{PET} / \mathrm{CT}$ scan compared to before was observed. The impact of CH-PET/CT on treatment decisions is illustrated in Figs. 3 and 4. Figure 3 shows a patient in
Table 3 PSA values in our patients (including the availability of the measurements) at selected time-points

\begin{tabular}{lllll}
\hline & At diagnosis & $\begin{array}{l}\text { Nadir after } \\
\text { treatment }\end{array}$ & $\begin{array}{l}\text { Before } \\
\text { CH-PET/CT }\end{array}$ & $\begin{array}{l}\text { End of } \\
\text { follow-up }\end{array}$ \\
\hline $\begin{array}{l}\text { No. of patients with value available } \\
\text { PSA (ng/ml) }\end{array}$ & $149 / 156$ & $139 / 156$ & $156 / 156$ & $156 / 156$ \\
Mean & 22.18 & 0.72 & 9.46 & 9.50 \\
Median & 12.00 & 0.10 & 3.40 & 0.91 \\
\hline
\end{tabular}




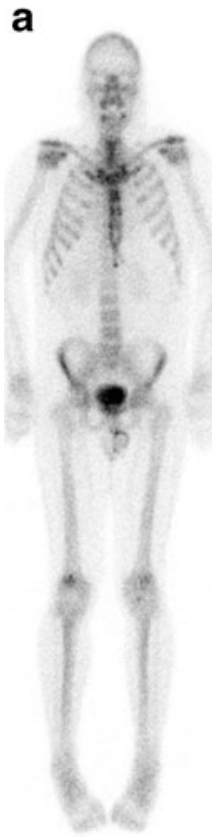

R ANTERIOR L

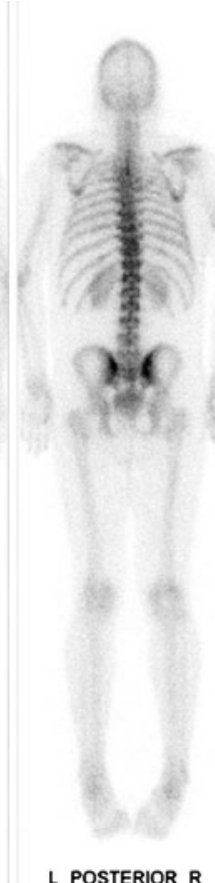

L POSTERIOR R
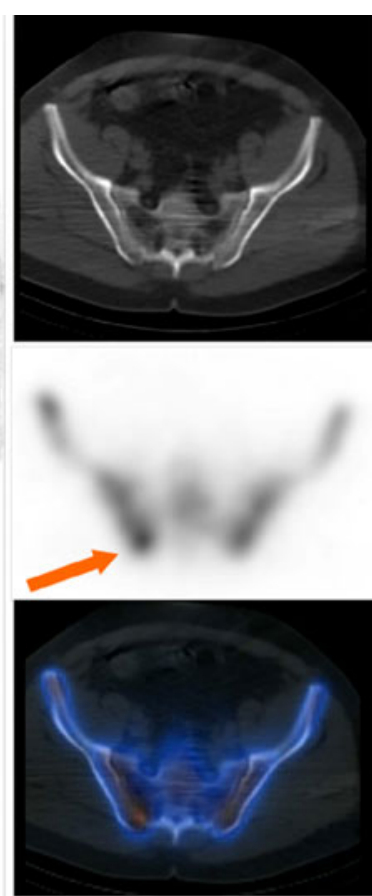

Fig. 3 A 53-year-old patient 6 years after surgery. PSA increasing to $3.0 \mathrm{ng} / \mathrm{ml}$. a Bone scintigraphy including SPECT/CT was read as negative including the right iliac bone (arrow). Thus local recurrence was suspected leading to a hypothetical treatment with radiation

whom CH-PET/CT showed bone metastasis leading to a change in treatment/management, and Fig. 4 shows a patient in whom $\mathrm{CH}-\mathrm{PET} / \mathrm{CT}$ confirmed local recurrence so that treatment/management was not changed.

Interestingly PSA ratios in patients with positive findings on CH-PET/CT were not significantly different from those in patients with negative findings, as was also the case in patients with therapeutic changes due to $\mathrm{CH}-\mathrm{PET} / \mathrm{CT}$ compared to those without. We believe that there are several factors which lead to these results. If patients had no findings on CH-PET/CT, the treatment in general followed the standard procedures for recurrent disease [6-8]. According to the guidelines in such a situation, if no other findings are present the decision whether a local or distant recurrence is present is made on the basis of the PSA kinetics. The standard procedures then are radiation therapy (if surgery was performed initially), antihormonal treatment, salvage resection, or combined approaches. After such a procedure the likelihood of success is high, especially since CH-PET/ CT (even though per definition false-negative due to rising PSA) has excluded gross metastatic spread. Thus it is not surprising that not only those patients with positive findings on CH-PET/CT but also those without detectable pathologies on CH-PET/CT had favourable PSA ratios. The situation in the subgroup of patients with therapeutic changes was quite similar to the situation in those without. If $\mathrm{CH}$ $\mathrm{PET} / \mathrm{CT}$ confirmed the suspected localization of recurrent b

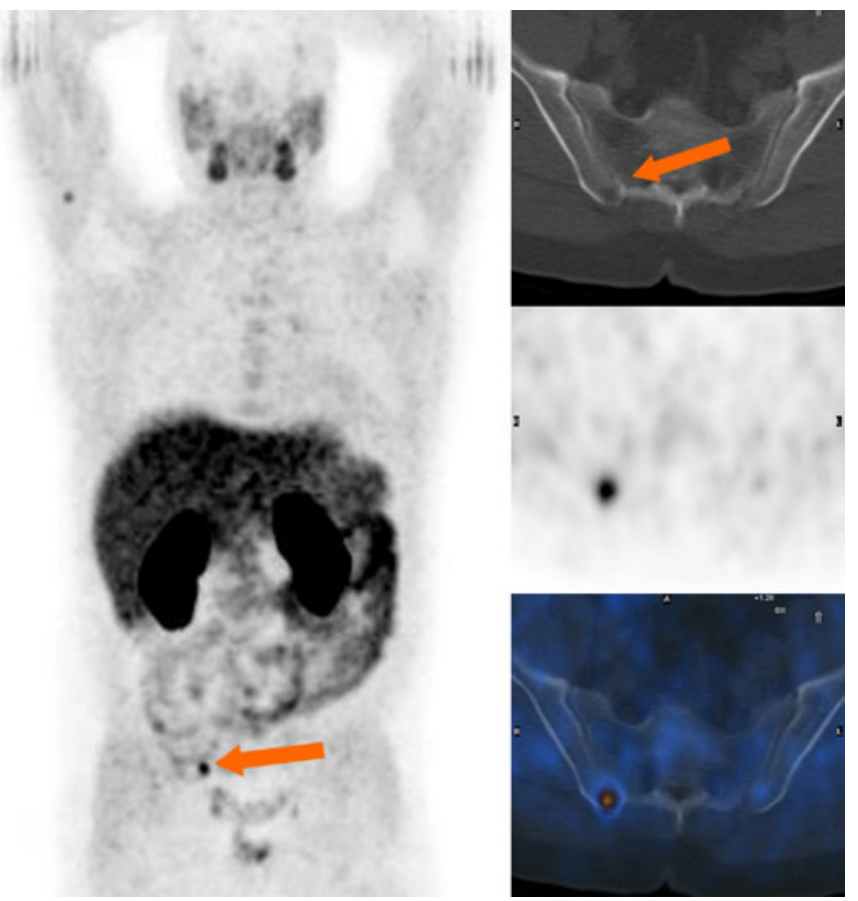

therapy of the small pelvis. b CH-PET/CT performed 4 weeks later revealed a metastasis in the iliac bone (arrows). The treatment plan was changed to radiation therapy of the iliac bone and additional antihormonal treatment. PSA declined to $2.45 \mathrm{ng} / \mathrm{ml}$
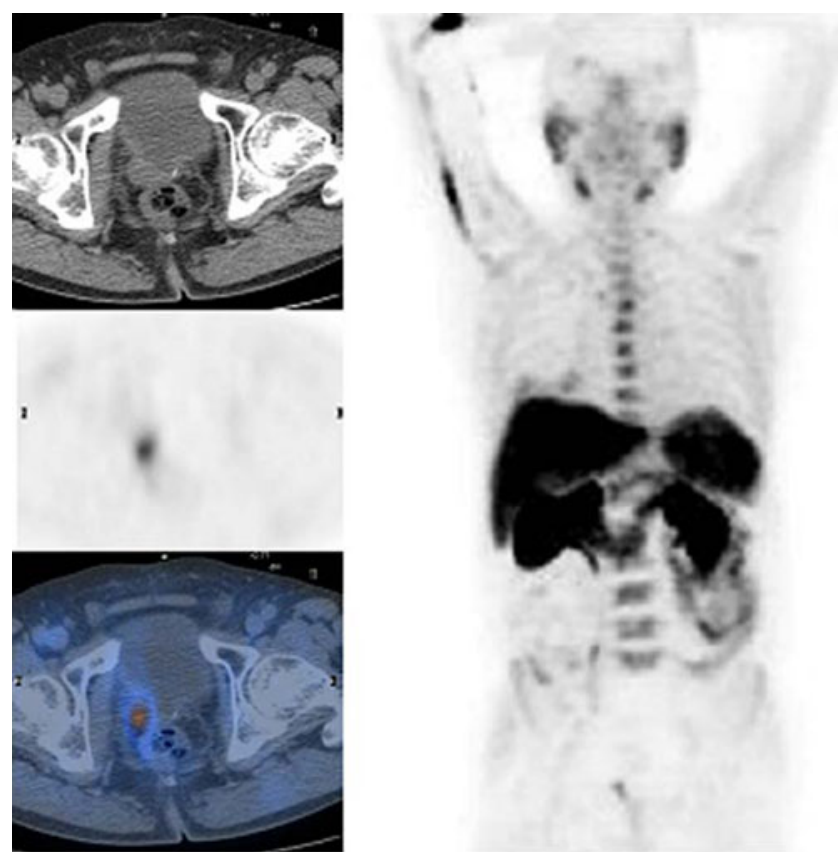

Fig. 4 A 74-year-old patient 3 years after surgery. PSA increasing to $2.2 \mathrm{ng} / \mathrm{ml}$. CH-PET/CT confirmed clinically suspected local recurrence. There was no change in the treatment plan. The patient received radiation therapy and the PSA declined to $0.43 \mathrm{ng} / \mathrm{ml}$ 
disease, no change in management occurred. The intended treatment approach remained correctly unchanged in these patients and the PSA ratios were of course as favourable as they were in those patients in whom CH-PET/CT demonstrated findings which led to a change in management. Therefore, it is clear that with our study set-up it is not possible to make statements about the influence of $\mathrm{CH}$ $\mathrm{PET} / \mathrm{CT}$ on the outcome of rPCA.

Interestingly in eight patients the referring physicians indicated changes in therapy even though CH-PET/CT demonstrated no positive findings. These results can be explained by the fact that despite the failure to detect recurrent disease, $\mathrm{CH}-\mathrm{PET} / \mathrm{CT}$ was able to exclude gross metastatic spread. This obviously led to changes in the planned treatment such as adaptation of the radiation field.

The major limitation of our study was its retrospective character. Our referring physicians were asked to retrospectively determine which therapy would have been performed if no CH-PET/CT scan findings had been available. There was potential bias, since the referring physicians were most likely to support the use of CH-PET/CT. Thus more favourable results regarding therapeutic changes could be assumed compared to a real prospective study design. Nevertheless, we believe that no serious bias was introduced into our study. First, according to the guidelines for PCA recurrence the therapeutic options are not very wide. They consist of radiation therapy, antihormonal treatment, salvage surgery, chemotherapy or a combination of these. There were two categories of patients referred for CH-PET/CT. The first category consisted of patients who had had a complete initial treatment with curative intent, recurrence and a salvage procedure, and in whom the PSA level had again risen. Following the guidelines in such a situation without further diagnostics only a palliative procedure with antihormonal treatment or watchful waiting would be advised. Any therapy aside from these two options was therefore very likely to be due to CH-PET/CT and a bias was basically only possible if a change in therapy occurred within the two palliative options, which was indicated in only 2 of 75 patients. The second category were patients whose PSA did not decline sufficiently or started rising again after initial curative therapy. In these potentially curable patients the standard procedure according to the guidelines is a salvage locoregional therapy mostly consisting of surgery or radiation therapy. Thus the indicated therapeutic changes from a curative to a palliative setting ( 15 of 75 patients) or within the same curative modality, such as extended lymphadenectomy or extended radiation field (16 of 75 patients), were most likely correct and not due to bias. The only potential for bias was in those patients in whom therapeutic changes were indicated from one curative setting to another ( 8 of 75 patients).
Conclusion

In our patient population CH-PET/CT in patients with $\mathrm{rPCA}$ had an important impact on the therapeutic strategy and was able to help determine an appropriate treatment in these patients.

Conflicts of interest None.

\section{References}

1. Jemal A, Bray F, Center MM, Ferlay J, Ward E, Forman D. Global cancer statistics. CA Cancer J Clin. 2011;61:69-90. doi:10.3322/ caac. 20107.

2. Lu-Yao GL, Potosky AL, Albertsen PC, Wasson JH, Barry MJ, Wennberg JE. Follow-up prostate cancer treatments after radical prostatectomy: a population-based study. J Natl Cancer Inst. 1996;88:166-73.

3. Bott SR. Management of recurrent disease after radical prostatectomy. Prostate Cancer Prostatic Dis. 2004;7:211-6. doi:10.1038/sj. pcan. 45007324500732 .

4. Fowler Jr FJ, Barry MJ, Lu-Yao G, Roman A, Wasson J, Wennberg JE. Patient-reported complications and follow-up treatment after radical prostatectomy. The National Medicare Experience: 1988-1990 (updated June 1993). Urology. 1993;42:622-9.

5. Freedland SJ, Humphreys EB, Mangold LA, Eisenberger M, Dorey FJ, Walsh PC, et al. Risk of prostate cancer-specific mortality following biochemical recurrence after radical prostatectomy. JAMA. 2005;294:433-9. doi:10.1001/jama.294.4.433.

6. Mottet N, Bellmunt J, Bolla M, Joniau S, Mason M, Matveev V, et al. EAU guidelines on prostate cancer. Part II: Treatment of advanced, relapsing, and castration-resistant prostate cancer. Eur Urol. 2011;59:572-83. doi:10.1016/j.eururo.2011.01.025.

7. Heidenreich A, Bellmunt J, Bolla M, Joniau S, Mason M, Matveev $\mathrm{V}$, et al. EAU guidelines on prostate cancer. Part 1: screening, diagnosis, and treatment of clinically localised disease. Eur Urol. 2011;59:61-71. doi:10.1016/j.eururo.2010.10.039.

8. National Comprehensive Cancer Network. NCCN clinical practice guidelines in oncology, prostate cancer. 2010. Fort Washington: National Comprehensive Cancer Network

9. Schmid DT, John H, Zweifel R, Cservenyak T, Westera G, Goerres $\mathrm{GW}$, et al. Fluorocholine PET/CT in patients with prostate cancer: initial experience. Radiology. 2005;235:623-8. doi:10.1148/ radiol.2352040494.

10. Picchio M, Briganti A, Fanti S, Heidenreich A, Krause BJ, Messa C, et al. The role of choline positron emission tomography/computed tomography in the management of patients with prostate-specific antigen progression after radical treatment of prostate cancer. Eur Urol. 2011;59:51-60. doi:10.1016/j.eururo.2010.09.004.

11. Fanti S, Krause B, Weber W, Castellucci P, Grosu AL, de Jong IJ, et al. Re: Nicolas Mottet, Joaquim Bellmunt, Michel Bolla, et al. EAU guidelines on prostate cancer. Part II: Treatment of advanced, relapsing, and castration-resistant prostate cancer. Eur Urol 2011;59:572-83. Eur Urol. 2011;60:e37-8; author reply e39-41. doi:10.1016/j.eururo.2011.08.009

12. Castellucci P, Fuccio C, Nanni C, Santi I, Rizzello A, Lodi F, et al. Influence of trigger PSA and PSA kinetics on 11C-choline PET/ $\mathrm{CT}$ detection rate in patients with biochemical relapse after radical prostatectomy. J Nucl Med. 2009;50:1394-400. doi:10.2967/ jnumed.108.061507. 
13. Krause BJ, Souvatzoglou M, Tuncel M, Herrmann K, Buck AK, Praus $\mathrm{C}$, et al. The detection rate of $[11 \mathrm{C}]$ choline-PET/CT depends on the serum PSA-value in patients with biochemical recurrence of prostate cancer. Eur J Nucl Med Mol Imaging. 2008;35:18-23. doi:10.1007/s00259-007-0581-4.

14. Husarik DB, Miralbell R, Dubs M, John H, Giger OT, Gelet A, et al. Evaluation of [(18)F]-choline PET/CT for staging and restaging of prostate cancer. Eur J Nucl Med Mol Imaging. 2008;35:253-63. doi:10.1007/s00259-007-0552-9.

15. Heinisch M, Dirisamer A, Loidl W, Stoiber F, Gruy B, Haim S, et al. Positron emission tomography/computed tomography with F18-fluorocholine for restaging of prostate cancer patients: meaningful at PSA $<5 \mathrm{ng} / \mathrm{ml}$ ? Mol Imaging Biol. 2006;8:43-8. doi:10.1007/s11307-005-0023-2.

16. Castellucci P, Fuccio C, Rubello D, Schiavina R, Santi I, Nanni C, et al. Is there a role for $11 \mathrm{C}$-choline PET/CT in the early detection of metastatic disease in surgically treated prostate cancer patients with a mild PSA increase $<1.5 \mathrm{ng} / \mathrm{ml}$ ? Eur J Nucl Med Mol Imaging. 2011;38:55-63. doi:10.1007/s00259-010-1604-0.
17. Souvatzoglou M, Krause BJ, Purschel A, Thamm R, Schuster T, Buck AK, et al. Influence of (11)C-choline PET/CT on the treatment planning for salvage radiation therapy in patients with biochemical recurrence of prostate cancer. Radiother Oncol. 2011;99:193-200. doi:10.1016/j.radonc.2011.05.005.

18. Wurschmidt F, Petersen C, Wahl A, Dahle J, Kretschmer M. [18F] Fluoroethylcholine-PET/CT imaging for radiation treatment planning of recurrent and primary prostate cancer with dose escalation to PET/CT-positive lymph nodes. Radiat Oncol. 2011;6:44. doi:10.1186/1748-717X-6-44.

19. Rigatti P, Suardi N, Briganti A, Da Pozzo LF, Tutolo M, Villa L, et al. Pelvic/retroperitoneal salvage lymph node dissection for patients treated with radical prostatectomy with biochemical recurrence and nodal recurrence detected by $[11 \mathrm{C}]$ choline positron emission tomography/computed tomography. Eur Urol. 2011;60:935-43. doi:10.1016/j.eururo.2011.07.060.

20. Kwee SA, Wei H, Sesterhenn I, Yun D, Coel MN. Localization of primary prostate cancer with dual-phase $18 \mathrm{~F}$-fluorocholine PET. J Nucl Med. 2006;47:262-9. 